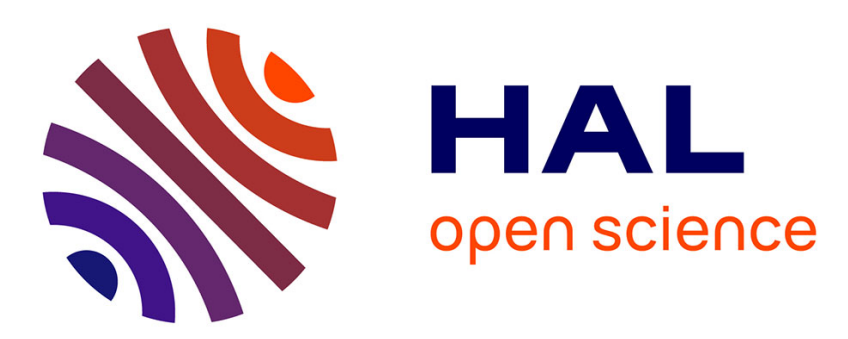

\title{
DISCREPANCY BETWEEN ACUTE AND CHRONIC TOXICITY INDUCED BY IMIDACLOPRID AND ITS METABOLITES IN APIS MELLIFERA
}

Séverine Suchail, David Guez, Luc P Belzunces

\section{- To cite this version:}

Séverine Suchail, David Guez, Luc P Belzunces. DISCREPANCY BETWEEN ACUTE AND CHRONIC TOXICITY INDUCED BY IMIDACLOPRID AND ITS METABOLITES IN APIS MELLIFERA. Environmental Toxicology and Chemistry, 2001, 20, pp.2482 - 2486. hal-02047800

\author{
HAL Id: hal-02047800 \\ https://hal-univ-avignon.archives-ouvertes.fr/hal-02047800
}

Submitted on 7 Mar 2019

HAL is a multi-disciplinary open access archive for the deposit and dissemination of scientific research documents, whether they are published or not. The documents may come from teaching and research institutions in France or abroad, or from public or private research centers.
L'archive ouverte pluridisciplinaire HAL, est destinée au dépôt et à la diffusion de documents scientifiques de niveau recherche, publiés ou non, émanant des établissements d'enseignement et de recherche français ou étrangers, des laboratoires publics ou privés. 


\title{
DISCREPANCY BETWEEN ACUTE AND CHRONIC TOXICITY INDUCED BY IMIDACLOPRID AND ITS METABOLITES IN APIS MELLIFERA
}

\author{
Séverine Suchail, David Guez, and Luc P. Belzunces* \\ INRA, Laboratoire de Toxicologie Environnementale, UMR INRA-UAPV Ecologie des Invertébrés, Site Agroparc, \\ 84914 Avignon Cedex 9, France
}

(Received 3 August 2000; Accepted 19 March 2001)

\begin{abstract}
Imidacloprid is a systemic nitroguanidine insecticide that belongs to the neonicotinoid family. As an agonist of the acetylcholine receptor, it attacks the insect nervous system and is extremely effective against various sucking and mining pests. Oral acute and chronic toxicity of imidacloprid and its main metabolites (5-hydroxyimidacloprid, 4,5-dihydroxyimidacloprid, desnitroimidacloprid, 6-chloronicotinic acid, olefin, and urea derivative) were investigated in Apis mellifera. Acute intoxication by imidacloprid or its metabolites resulted in the rapid appearance of neurotoxicity symptoms, such as hyperresponsiveness, hyperactivity, and trembling and led to hyporesponsiveness and hypoactivity. For acute toxicity tests, bees were treated with doses of toxic compounds ranging from 1 to $1,000 \mathrm{ng} / \mathrm{bee}(10-10,000 \mu \mathrm{g} / \mathrm{kg}$ ). Acute toxicity (LD50) values of imidacloprid were about 60 $\mathrm{ng} / \mathrm{bee}(600 \mu \mathrm{g} / \mathrm{kg})$ at $48 \mathrm{~h}$ and about $40 \mathrm{ng} / \mathrm{bee}(400 \mu \mathrm{g} / \mathrm{kg})$ at 72 and $96 \mathrm{~h}$. Out of the six imidacloprid metabolites tested, only two (5-hydroxyimidacloprid and olefin) exhibited a toxicity close to that of imidacloprid. Olefin LD50 values were lower than those of imidacloprid. The 5-hydroxyimidacloprid showed a lower toxicity than imidacloprid with a LD50 four to six times higher than that of imidacloprid. Urea also appeared as a compound of nonnegligible toxicity by eliciting close to $40 \%$ mortality at 1,000 $\mathrm{ng} / \mathrm{bee}(10,000 \mu \mathrm{g} / \mathrm{kg})$. However, no significant toxicity was observed with 4,5-dihydroxyimidacloprid, 6-chloronicotinic acid, and desnitroimidacloprid in the range of doses tested. To test chronic toxicity, worker bees were fed sucrose solutions containing 0.1, 1 , and $10 \mu \mathrm{g} / \mathrm{L}$ of imidacloprid and its metabolites for $10 \mathrm{~d}$. Fifty percent mortality was reached at approximately $8 \mathrm{~d}$. Hence, considering that sucrose syrup was consumed at the mean rate of $12 \mu \mathrm{l} / \mathrm{d}$ and per bee, after an 8 -d period the cumulated doses were approximately $0.01,0.1$, and $1 \mathrm{ng} / \mathrm{bee}(0.1,1$, and $10 \mu \mathrm{g} / \mathrm{kg})$. Thus, all tested compounds were toxic at doses 30 to 3,000 (olefin), 60 to 6,000 (imidacloprid), 200 to 20,000 (5-OH-imidacloprid), and >1,000 to 100,000 (remaining metabolites) times lower than those required to produce the same effect in acute intoxication studies. For all products tested, bee mortality was induced only $72 \mathrm{~h}$ after the onset of intoxication.
\end{abstract}

Keywords-Imidacloprid Metabolite Honeybee Chronic toxicity Acute toxicity

\section{INTRODUCTION}

The honeybee, Apis mellifera, plays a major role in crop pollination and produces valuable agricultural products (honey, pollen, royal jelly, propolis, and wax) [1]. Chemical pesticides also play a central role in the modern agricultural ecosystem. Unfortunately, the two are not always compatible because the pollinators are often more sensitive to poisoning than the target pests, if not more so [2,3]. The hazard of different chemicals is commonly expressed in terms of acute toxicity (LD50). The hazard of pesticide poisoning to honeybees results not only from direct contact poisoning but also from the intake of certain contaminated nectar, pollen, and water and the transport of contaminated products into the hive. Bee colony exposure to repeated low doses of pesticides may have serious long-term consequences, including depletion of hive bees and even death of the entire colony. It is important to be able to identify the risks associated with honeybee exposure to very low pesticide doses. Low pesticide doses can affect individual bees by disrupting their ability to communicate the location of nectar and pollen sources or by shortening their life spans. Worker bee longevity might be used as a parameter to measure sublethal effects [4]. Since pesticides remain toxic in the environment for a period of time that is inversely proportionate to the intensity of their biological and physicochemical degradation, multiple testing was needed to evaluate their toxicity

* To whom correspondence may be addressed (belzunce@avignon.inra.fr). to honeybees. This prompted the European and Mediterranean Plant Protection Organization and the European Community to improve the assessment of pesticide-related risks to bees $[5,6]$.

Imidacloprid is a nitroguanidine systemic insecticide that belongs to the neonicotinoid family. It acts as an agonist of the acetylcholine receptor and is known to have a very selective toxicity, which is attributable mostly to its higher affinity for the insect than for the vertebrate nicotinic acetylcholine receptor [7-9]. Imidacloprid is extremely effective against various sucking and mining pests. Exposure to this compound can be through contact or ingestion. Its excellent systemic properties and lasting action make it suitable for foliar, soil, and seed treatments [10]. Thanks to its systemic properties, imidacloprid is transported mainly through the xylem in young and growing plants. After spray treatment, the main residue on the leaf surface was the parent compound, whereas after soil and seed treatment, imidacloprid was metabolized, more or less completely according to plant species and time, into several different metabolites, all of which contained elements of the 6-chloropyridine group (Table 1) [11]. Spraying can contaminate nectar and poison honeybees either through direct contact with the product or through contact with its residue. Seed dressing can also poison honeybees through oral contact with the parent compound or metabolite compounds. Experiments with seed-treated cotton plants revealed that the young plant took up only $5 \%$ of the imidacloprid applied and that approximately $95 \%$ of the parent compound was metabolized 
Table 1. Lethal dose, 50\% (LD50) values of imidacloprid in Apis mellifera (ng/bee). The LD50 values were obtained from experiments carried out with different imidacloprid doses in oral acute application. LD50 values were calculated by log-probit analysis. Values represented means of three experiments performed in triplicate \pm standard deviation

\begin{tabular}{lccccccc}
\hline & Imidacloprid & 5-Hydroxy & Olefin & 4,5-Dihydroxy & Desnitro & 6-CNA & Urea $^{\text {a }}$ \\
\hline $48 \mathrm{~h}$ & $57 \pm 28$ & $258 \pm 7$ & $28 \pm 19$ & $>1,000$ & $>1,000$ & $>1,000$ & $>1,000$ \\
$72 \mathrm{~h}$ & $37 \pm 10$ & $206 \pm 26$ & $29 \pm 3$ & $>1,000$ & $>1,000$ & $>1,000$ & $>1,000$ \\
$96 \mathrm{~h}$ & $37 \pm 10$ & $222 \pm 25$ & $23 \pm 6$ & $>1,000$ & $>1,000$ & $>1,000$ & $>1,000$ \\
\hline
\end{tabular}

${ }^{\mathrm{a}} \mathrm{CNA}=$ chloronicotinic acid.

$27 \mathrm{~d}$ after sowing [12]. Some imidacloprid metabolites produced by plants have shown a toxicity level close to that of imidacloprid. On the green peach aphid, Myzus persicae, and the cotton aphid, Aphis gossypii, olefin and the nitroso-derivative showed a 16 times and 6 times higher activity than imidacloprid (based on 48-h lethal concentration $50 \%$ values) [13].

A previous study on acute oral and contact toxicity of imidacloprid showed important characteristics. With the two application modes, an unusual honeybee mortality profile was observed: Mortality rose with low doses, fell with intermediate doses, and rose again with high doses. Moreover, the kinetics of mortality was delayed as doses increased. These features suggest that several metabolic pathways might be involved in imidacloprid toxicity [14]. The oral acute toxicity tests take into account the risk of pesticides to honeybees and make it possible to rank active substances according to their toxicity. These toxicity tests can also be used to determine the sublethal level of insecticide. Oral chronic studies permit one to observe the long-term toxicity of pesticide residual activity induced by low doses in honeybees. Therefore, acute toxicity and residual activity combined give a good measure of active substance hazard to honeybees. In order to evaluate the impact of imidacloprid on honeybees, oral acute and chronic toxicity of imidacloprid and its main metabolites to worker honeybees were compared. In chronic study, we used concentrations of imidacloprid and metabolites close to those found in plants after treatments with imidacloprid [15].

\section{MATERIALS AND METHODS}

\section{Materials}

Imidacloprid of the highest purity available was used, and the purity of the imidacloprid metabolites (Fig. 1) was at least 97\%. Bayer AG (Leverkussen, Germany) supplied both. For<smiles>O=[N+]([O-])N=c1[nH]ccn1Cc1ccc(Cl)nc1</smiles><smiles>N=C1NCCN1Cc1ccc(Cl)nc1</smiles>

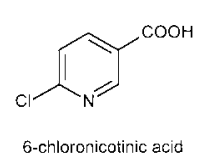

Fig. 1. Structures of imidacloprid and the studied metabolites. all bioassays, worker bees (A. mellifera) were captured from honey and pollen combs in a healthy queen-right colony; all drones were discarded. Immediately before treatment, bees were anaesthetized with carbon dioxide and kept in cages (10.5 $\times 7.5 \times 11.5 \mathrm{~cm})$ in a temperature-controlled chamber at 25 $\pm 2^{\circ} \mathrm{C}$ with $60 \pm 10 \%$ relative humidity. Bees were fed a $50 \%$ sucrose solution ad libitum [16].

\section{Experimental conditions}

In each experiment, three cages of 20 bees and 30 bees were used for each dose of treatment for oral acute and chronic studies, respectively. To avoid intercolony and seasonal variations, chronic and acute toxicity studies were conducted at the same time with bees captured from the same colony. Experiments were replicated at least three times. Repetitions were within one week.

\section{Mode of treatment}

Imidacloprid and its metabolite solutions were prepared in a $1 \%$ dimethylsulfoxide solution and then diluted 10 -fold in the $50 \%(\mathrm{w} / \mathrm{v})$ feeding sucrose solution. The final concentration of dimethylsulfoxide in the sucrose solutions for the control and assay tests was $0.1 \%(\mathrm{v} / \mathrm{v})$. Fresh dosing solutions were prepared for each test. In all studies, bees were kept in the obscurity at $25 \pm 1.5^{\circ} \mathrm{C}$ and $65 \%$ relative humidity. The honeybees were deprived of food for $2 \mathrm{~h}$ before administration of the active substance. For acute toxicity, each bee received $10 \mu \mathrm{l}$ of $50 \%$ sucrose solution (vehicle) containing graded doses of imidacloprid or its metabolites or the dosing vehicle alone (control). After consuming this solution, bees were fed $50 \%$ straight sucrose solution ad libitum. Mortality was recorded at 2, 4, 6, 10, 14, 20, 24 30, 48, 72, and $96 \mathrm{~h}$. The LD50 was determined by plotting the probit values of percentages of mortality against the logarithm of the dose. For chronic toxicity studies, bees were continuously fed 50\% (w/ v) sucrose solution containing or not the tested substances during $10 \mathrm{~d}$. During the experiments, feeders were changed daily with fresh sucrose solutions containing the products tested. To avoid photodecomposition, opaque feeders were used. The individual daily consumption of the sucrose solution was determined by weighing the feeders and was corrected by the surviving bees. Cumulated doses were calculated directly from sucrose solution consumption, the concentration of the products tested, and the density of the sucrose solution.

\section{Data analysis}

Mortality values were corrected according to the Abbott formula [17]:

$$
M=\frac{(T-C)}{S} \times 100
$$

where $M$ is the percentage of corrected mortality, $T$ the mor- 
tality of treated bees, $C$ the mortality of the control bees, and $S$ the surviving control bees.

\section{RESULTS}

After acute intoxication by imidacloprid or its metabolites, early symptoms of neurotoxicity were observed. They include hyperresponsiveness, hyperactivity, and trembling. After several hours, these symptoms gradually disappeared, and the worker bees became hyporesponsive and hypoactive.

Oral acute toxicity tests were used to determine LD50 values and to compare metabolites toxicity with that of the parent compound. The LD50 values of imidacloprid were $57 \pm 28$ $\mathrm{ng} / \mathrm{bee}(570 \pm 280 \mu \mathrm{g} / \mathrm{kg})$ at $48 \mathrm{~h}$ and $37 \pm 10 \mathrm{ng} / \mathrm{bee}(370$ $\pm 100 \mu \mathrm{g} / \mathrm{kg}$ ) at 72 and $96 \mathrm{~h}$. Only two imidacloprid metabolites (5-hydroxyimidacloprid and olefin) exhibited a toxicity close to that of imidacloprid. The LD50 values of 5-hydroxyimidacloprid were $258 \pm 7 \mathrm{ng} /$ bee $(2,580 \pm 70 \mu \mathrm{g} / \mathrm{kg})$ at 48 h, $206 \pm 26 \mathrm{ng} / \mathrm{bee}(2,060 \pm 260 \mu \mathrm{g} / \mathrm{kg})$ at $72 \mathrm{~h}$, and $222 \pm$ $25 \mathrm{ng} / \mathrm{bee}(2,220 \pm 250 \mu \mathrm{g} / \mathrm{kg})$ at $96 \mathrm{~h}$. Olefin LD50 values were $28 \pm 19 \mathrm{ng} / \mathrm{bee}(280 \pm 190 \mu \mathrm{g} / \mathrm{kg})$ at $48 \mathrm{~h}, 29 \pm 3 \mathrm{ng} /$ bee $(290 \pm 30 \mu \mathrm{g} / \mathrm{kg})$ at $72 \mathrm{~h}$, and $23 \pm 6 \mathrm{ng} / \mathrm{bee}(230 \pm 60$ $\mu \mathrm{g} / \mathrm{kg})$ at $96 \mathrm{~h}$. Thus, imidacloprid was more toxic than 5hydroxyimidacloprid and less toxic than olefin. The toxicity of urea was also significant with $40 \%$ mortality induced at $1,000 \mathrm{ng} / \mathrm{bee}(10,000 \mu \mathrm{g} / \mathrm{kg})$. However, no significant toxicity was observed with 4,5-dihydroxyimidacloprid, 6-chloronicotinic acid, and desnitroimidacloprid.

Chronic toxicity was studied during a 10 -d period. For all products tested, mortality in the control group was under $15 \%$ in all experiments, as recommended in European and Mediterranean Plant Protection Organization guidelines. Results obtained revealed some particular unexpected characteristics (Fig. 2). Surprisingly, the chronic oral test showed that imidacloprid and all studied metabolites were toxic. Bee mortality was induced only $72 \mathrm{~h}$ after the onset of intoxication. Imidacloprid and its metabolites exhibited similar long-term toxicity. For imidacloprid, toxicity was similar with concentrations of 1 and $10 \mu \mathrm{g} / \mathrm{L}$, whereas with $0.1 \mu \mathrm{g} / \mathrm{L}$ of imidacloprid, the mortality rate was lower. With 5-hydroxyimidacloprid, mortality increased with the concentration. With the other metabolites, olefin, 4,5-dihydroxyimidacloprid, desnitroimidacloprid, 6-chloronicotinic acid, and urea, mortality evolution was similar during $10 \mathrm{~d}$ for all concentrations tested.

In chronic experiments, each honeybee ingested approximately $12 \mu \mathrm{l}$ of contaminated sucrose solution per day. Therefore, for the concentration of the toxic compounds of $0.1,1$, and $10 \mu \mathrm{g} / \mathrm{L}$, each honeybee ingested $0.010,0.1$, and $1 \mathrm{ng}$ of compound per day, respectively.

\section{DISCUSSION}

Workers bees exposed to insecticides exhibit several symptoms. With imidacloprid, neurotoxicity symptoms, such as movement coordination problems, trembling, and tumbling, appear rapidly. After several hours, these symptoms gradually disappear, and the worker bees become hyporesponsive and hypoactive. After imidacloprid application, the German cockroach, a Coleoptera Blattella germanica, apparently exhibit comparable behavior, that is, early symptoms of poisoning, including hyperresponsiveness, hyperactivity, and tremors of the body and legs followed by ataxia [18].

In the present study, the imidacloprid LD50 value obtained in A. m. mellifera after oral application is about $60 \mathrm{ng} / \mathrm{bee}$ $(600 \mu \mathrm{g} / \mathrm{kg})$. In previous studies, oral LD50 was equal to about
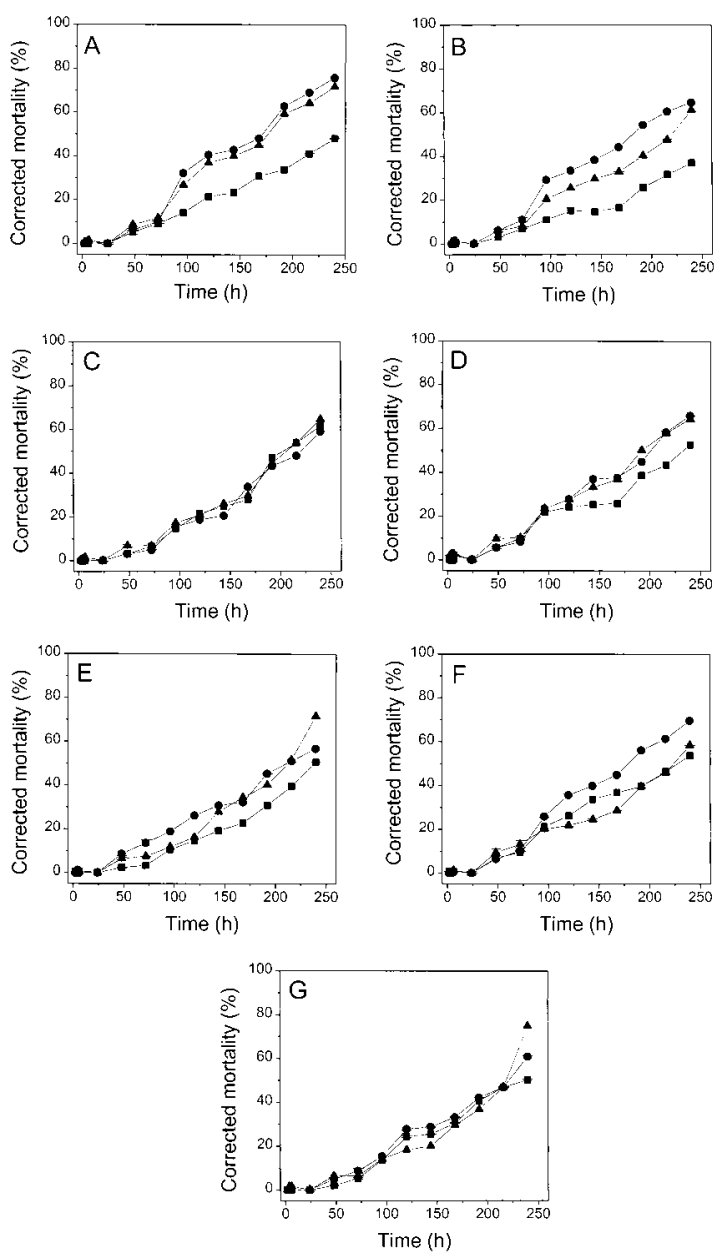

Fig. 2. Mortality kinetics in Apis mellifera during chronic exposure to imidacloprid (A), 5-hydroxyimidacloprid (B), olefin (C), 4,5-dihydroxyimidacloprid (D), 6-chloronicotinic acid (E), desnitroimidacloprid $(\mathbf{F})$, and urea derivative $(\mathbf{G})$. Bees were fed $50 \%$ sucrose solution containing imidacloprid or its metabolites at concentrations of 0.1 (squares), 1 (circles), or $10 \mu \mathrm{g} / \mathrm{L}$ (triangles). Data represented the means of three experiments performed in triplicate \pm standard deviation. For each repetition, mortality of the control did not exceed $15 \%$. The absence of error bar corresponds to standard deviation $=0$.

$5 \mathrm{ng} / \mathrm{bee}(50 \mu \mathrm{g} / \mathrm{kg})$ [14]. Thus, the acute toxicity (LD50) studies show that imidacloprid sensitivity varied from one honeybee colony to the other. With most of the insecticides, LD50 values vary by a factor of two, whereas for imidacloprid acute toxicity, the factor is over 100. Although imidacloprid LD50 of about 5 (worse case) or $60 \mathrm{ng} / \mathrm{bee}$ (usual case) (50 or 600 $\mu \mathrm{g} / \mathrm{kg}$ ) are found, LD50 values may vary from colony to colony and can range from 5 to $500 \mathrm{ng} / \mathrm{bee}(50-5,000 \mu \mathrm{g} / \mathrm{kg}$ ) (data not shown). However, we observed that when the dosemortality curve presents two ascending parts, the oral LD50 of imidacloprid is close to $5 \mathrm{ng} / \mathrm{bee}(50 \mu \mathrm{g} / \mathrm{kg})$. When a classical dose-mortality curve is observed, the LD50 of imidacloprid is close to $70 \mathrm{ng} / \mathrm{bee}(700 \mu \mathrm{g} / \mathrm{kg})$ [14]. This difference of imidacloprid sensitivity from colony to colony can be due to a variation in detoxification capacity in honeybee colonies. Schonbrod et al. [19] studied the relationship between acute toxicity and mono-oxygenase levels in preselected strains of houseflies. They concluded that no clear relationship existed between mono-oxygenase activity and insecticide resistance in this insect. On the other hand, in the honeybee, Smirle et al. [20] showed that a significant linear relationship existed 
between the acute toxicity of an organophosphorus insecticide, the diazinon, and colony polysubstrate mono-oxygenase activity. The variation in detoxification capacity in honeybee colonies was a significant factor in determining resistance to diazinon. Thus, intracolony variations of imidacloprid sensitivity can be explained by the difference in oxidative metabolisms between honeybee colonies.

Because of its large range of LD50 values, imidacloprid is difficult to categorize. However, the comparison of its low LD50 with the LD50 of two of the most toxic insecticides, the organophosphorus compound dimethoate (oral LD50 = $152 \mathrm{ng} / \mathrm{bee}, 1,520 \mu \mathrm{g} / \mathrm{kg}$ ) and the pyrethroid cypermethrin (oral LD50 = $160 \mathrm{ng} / \mathrm{bee}, 1,600 \mu \mathrm{g} / \mathrm{kg}$ ), categorizes it as one of the most toxic insecticides to honeybees $[21,22]$. Imidacloprid, thus, is one of the most potent insecticides to honeybees and should not be applied during the flowering period [10]. Applications by seed dressing and granules decrease the hazard to honeybees. In acute tests, bee mortality induced by imidacloprid begins to appear generally $4 \mathrm{~h}$ after intoxication and increases progressively during $100 \mathrm{~h}$, whereas the symptoms of intoxication appear more rapidly. The uncoupling between symptoms and the appearance of toxicity in insects is somewhat surprising. In most cases, we have observed that the maximum effect with neurotoxic insecticides, such as organophosphorus, organochlorine, carbamate, and pyrethroid compounds, is obtained between 0.5 and $5 \mathrm{~h}$ following intoxication. Imidacloprid has either a prolonged action or a delayed action, but symptoms are always immediate. The discrepancy between mortality kinetics and the rapid appearance of symptoms could be explained by the long-term residual effectiveness of imidacloprid, the action of toxic imidacloprid metabolites, or the fact that early symptoms are due to imidacloprid itself while mortality is induced by a metabolite. Prolonged imidacloprid action has been also observed in other invertebrates. Hu et al. [23] showed that mortality in flies peaked about $4 \mathrm{~d}$ following exposure, indicating a relatively slow action. Thus, imidacloprid seems to be a long-acting compound, and in many invertebrates its effect continues long after intoxication.

Acute studies showed that only two imidacloprid metabolites, olefin and 5-hydroxyimidacloprid, were toxic to honeybees. This result might be explained by the fact that imidacloprid and these two metabolites have a similar chemical structure. The 5-hydroxyimidacloprid was as toxic as imidacloprid; olefin was more toxic. In acute tests, about $60 \mathrm{ng}$ of imidacloprid, $200 \mathrm{ng}$ of 5-hydroxyimidacloprid, or $30 \mathrm{ng}$ of olefin per bee are needed to induce $50 \%$ mortality, whereas with all other metabolites, $50 \%$ mortality can be obtained only with doses above $1,000 \mathrm{ng} / \mathrm{bee}(10,000 \mu \mathrm{g} / \mathrm{kg})$. Surprisingly, chronic tests show that imidacloprid and all its studied metabolites are toxic to honeybees. In chronic studies, $50 \%$ of mortality is obtained after $8 \mathrm{~d}$ of exposure to the toxic compounds during which each bee ingested about $12 \mu \mathrm{l}$ of contaminated solution per day. Hence, at concentrations of 0.1 , 1 , and $10 \mu \mathrm{g}$ of toxic compound per liter, the total cumulated dose ingested by the bees in chronic intoxication is about 30 to 3,000 (olefin), 60 to 6,000 (imidacloprid), 200 to 20,000 (5-OH-imidacloprid), and $>1,000$ to 100,000 (remaining metabolites) times lower than the doses needed to produce the same effect in acute intoxication tests.

Toxicity such as that caused by imidacloprid has been previously observed with other insecticides in honeybees. Fiedler [24] studied chronic toxicity of organophosphorus insecticides to honeybees. For acephate, methamidophos, and dimethoate, the cumulated dose resulting in a mortality of $50 \%$ was lower than the acute oral LD50 at $24 \mathrm{~h}$. With $5 \mathrm{ng}$ acephate consumed daily (which is equivalent to only $2.5-5 \%$ of the LD50), a mortality of $68 \%$ after $14 \mathrm{~d}$ was observed. Moreover, Illarionov [25] has compared the toxicity induced by organophosphorus compounds and pyrethroids in honeybees in the case of single and multiple ingestions of contaminated solutions. This study showed that the toxicity to worker bees was higher in the case of multiple ingestion of food containing the active substance than in the case of a single ingestion. For pyrethroids, LD50 values were increased by a factor of 150 for alphamethrin and 1,500 for cypermethrin. For organophosphorus compounds, LD50 values increased by extremes of 220 and 570 times for volaton and actellic, respectively. Different hypotheses can explain mortality induced over time in a long-term period with low doses of imidacloprid metabolites. One explanation could be that lower doses of active substance are not high enough to induce detoxification mechanisms, whereas high doses can induce detoxification enzymes to detoxify the parent compound, which normally induce a lower toxicity. In our study, the toxicity of low doses of all imidacloprid metabolites studied makes this hypothesis less likely. Our results strongly suggest two levels of action for imidacloprid and its metabolites, involving high- and low-affinity receptors. Low doses can activate a high-affinity receptor, thus inducing mortality. Higher doses can activate both the high- and the low-affinity receptors; the latter could have an opposite compensating action that would induce a protective effect. The existence of different sites has already been proposed by Nagata et al. [26], who suggest that imidacloprid may have an agonistic effect at low doses and an antagonistic effect at higher doses. This hypothesis is in accordance with the results obtained by Benson [27] showing that 1-(pyridin-3-yl-methyl)-2-nitromethylene-imidazolidine, a nitromethylene structurally close to imidacloprid, presents agonistic and antagonistic effects at high and low concentrations in Locusta. These effects at high and low concentrations strongly suggest the existence of high- and lowaffinity imidacloprid-binding sites. Such binding sites have been demonstrated in Myzus and Nephotettix (both Hemiptera) and present dissociation constants of approximately 0.1 and $10 \mathrm{nM}$ [28]. The difference in the affinity of the binding sites could account for the difference of a factor 100 in the antagonistic and agonistic levels of action observed with 1-(pyridin3-yl-methyl)-2-nitromethylene-imidazolidine. Since most of the insects present only low-affinity binding sites, Lind et al. [28] suggest that the high imidacloprid toxicity to hemipteran pests may be due specifically to the presence of both low- and high-affinity binding sites. Hence, the high toxicity of imidacloprid and its metabolites, at very low doses, to honeybees could reflect the existence of binding sites with different affinities.

The present results suggest that imidacloprid and the metabolites that resemble it (olefin and 5-hydroxyimidacloprid) and that could fit imidacloprid receptors might act on the same biological system activated at high doses. Conversely, all compounds, including imidacloprid, may act on a high-affinity receptor because they induce mortality at very low doses. It is assumed that this receptor would be more specific of the 2chloropyridine part because 6-chloronicotinic acid also induces mortality at low doses.

In the experiment of chronic toxicity, no marked dose effect is observed. This cannot be explained by variability in the biological material or by the large amplitude range of respons- 
es since no great variability in results was observed, although the study was repeated three times with triplicate treatment conditions each time (Fig. 1). The absence of a marked dose effect could be explained by the fact that the maximum kinetic rate of mortality could already have been reached from the lowest doses, 0.1 or $1 \mu \mathrm{g} / \mathrm{L}$. Another plausible explanation is that, as the low doses increase, the response progressively approaches that elicited by high doses whose observed toxicity rate is lower.

The results obtained in this study raise some questions: Is mortality induced by imidacloprid, its metabolites, or both? Do imidacloprid and its metabolites bind to identical or different receptors? Do we have to revisit the notion of pertinent metabolite, considering the low level of action of imidacloprid metabolites? Considering the appearance kinetic of metabolites in plants, is a delayed toxicity possible? Such a delayed toxicity would be in accordance with the prolonged control of aphids observed with imidacloprid-treated plants in both the glasshouse and the field. This persistence of prolonged action seems to be due to both imidacloprid and the olefin metabolite, which has recently been shown to have greater aphicidal effectiveness than imidacloprid.

In the future, it would be interesting to follow imidacloprid metabolism in different parts of A. mellifera to observe a possible accumulation of imidacloprid or its metabolites in specific compartments of the honeybee. Thus, this would allow a better characterization of the imidacloprid toxicodynamic in the honeybee. Moreover, a better understanding of interactions between imidacloprid metabolites and their receptors could make it possible to determine if imidacloprid and its metabolites bind to the same receptor and if toxicity is due to imidacloprid alone, to the action of one or more selected metabolites, or to the combined action of imidacloprid and its metabolites.

Acknowledgement-This work was supported in part by a Conventions Industrielles de Formation par la Recherche agreement between Institut National de la Recherche Agronomique and Bayer AG. We thank Magali Rault-Léonardon for her critical reading of the manuscript and Léonie Forestier for her technical help.

\section{REFERENCES}

1. Free JB. 1993. Insect Pollination. Academic, New York, NY, USA.

2. Johansen CA. 1977. Pesticides and pollinators. Annu Rev Entomol 22:177-192.

3. National Research Council of Canada. 1981. Pesticide-pollinator interactions. NRCC-18471. Environmental Secretariat, Ottawa, ON, Canada.

4. Smirle MJ, Winston ML, Woodward KL. 1984. Development of sensitive bioassay for evaluation of pesticide effects on the honeybee (Hymenoptera; apidae). J Econ Entomol 77:63-67.

5. European and Mediterranean Plant Protection Organization. 1993. Decision-making scheme for the environmental risk assessment of plant protection products. EPPO Bull 23:151-156.

6. European Community. 1996. Council Directive 91/414/EEC. Concerning the placing of plant protection products on the market. Office for Official Publications of the European Communities, Luxembourg, Belgium.

7. Liu MY, Casida JE. 1993. High affinity binding of [3H]-imida- cloprid in the insect acetylcholine receptor. Pestic Biochem Physiol 46:40-46.

8. Tomizawa M, Otsuka H, Miyamoto T, Yamamoto I. 1995. Pharmacological effects of imidacloprid and its related compounds on the nicotinic acetylcholine receptor with its ion channel from the Torpedo electric organ. J Pestic Sci 20:49-56.

9. Zwart R, Oortgiesen M, Vijverberg HPM. 1994. Nitromethylene heterocycles: Selective agonists of nicotinic receptors in locust neurons compared to mouse N1E-115 and BC3H1 cells. Pestic Biochem Physiol 48:202-213.

10. Pflueger W, Schmuck R. 1991. Ecotoxicological profile of imidacloprid. Pflanzenschutz-Nachr Bayer 44:145-158.

11. Araki Y, Bornatsch W, Brauner A, Clark T, Dräger G, Kurogochi S, Sakamato H, Vogeler K. 1994. Metabolism of imidacloprid in plants. Proceedings, IUPAC Congress, Washington, DC, July 49, pp 2B-157.

12. Tröltzsch CM, Fürh F, Wieneke J, Elbert A. 1994. Influence of various irrigation procedures on the uptake of imidacloprid by cotton after seed treatment. Pflanzenschutz-Nachr Bayer 47:249303.

13. Nauen R, Tiejen K, Wagner K, Elbert A. 1998. Efficacy of plant metabolites of imidacloprid against Myzus persicae and Aphid gossypii (Homoptera: Aphididae). Pestic Sci 52:53-57.

14. Suchail S, Guez D, Belzunces LP. 2000. Characteristics of imidacloprid toxicity in two Apis mellifera subspecies. Environ Toxicol Chem 19:1901-1905.

15. European and Mediterranean Plant Protection Organization. 1992. Guidelines on test methods for evaluating the side effects of plant protection products on honeybees. EPPO Bull 22:203-215.

16. Abbott WS. 1925. A method of computing the effectiveness of an insecticide. J Econ Entomol 18:265-267.

17. Klaus W. 2000. Tests regarding the danger of the seed disinfectant, Gaucho, for bees. Proceedings, ICPBR 7th Bee Protection Symposium, Avignon, France, September 7-9, p 46.

18. Wen Z, Scott JG. 1997. Cross-resistance to imidacloprid in strains of German Cockroach (Blattella germanica) and house fly (Musca domestica). Pestic Sci 49:367-371.

19. Schronbrod RD, Khan MAQ, Terriere LC, Plapp FW. 1968. Microsomal oxidases in the house fly: A survey of fourteen strains. J Econ Entomol 77:833-837.

20. Smirle MJ, Winston ML. 1987. Intercolony variation in pesticide detoxification by the honeybee (Hymenoptera: Apidae). J Econ Entomol 80:5-8.

21. Jaycox ER. 1964. Effect on honeybees of nectar from systemic insecticide-treated plants. J Econ Entomol 57:31-35.

22. Bendahou N, Bounias M, Fleche C. 1997. Acute toxicity of cypermethrin and fenitrothion on honeybees (Apis mellifera mellifera) according to age, formulations and (chronic paralysis virus)/insecticide interaction. J Environ Biol 18:55-65.

23. Hu XP, Propoky RJ. 1998. Lethal and sublethal effects of imidacloprid on apple maggot fly, Rhagoletis pomonella Walsh (Dipt., Tephritidae) J Appl Entomol 122:37-42.

24. Fiedler L. 1987. Assessment of chronic toxicity of selected insecticides to honeybees. J Apic Res 26:115-122.

25. Illarionov AI. 1991. Toxic effects of some insecticides on the honeybee. Agrokhimiya 8:121-125.

26. Nagata K, Song JH, Shono T, Narahashi T. 1998. Modulation of the neuronal nicotinic acetylcholine receptor-channel by the nitromethylene heterocycle imidacloprid. J Pharmacol Exp Ther 285:731-738.

27. Benson JA. 1989. Insect nicotinic acetylcholine receptors as targets for insecticides. In Mc Farlane NE, ed, Progress and Prospects in Insect Control. BCPC Monograph 43. British Crop Protection Council, Farnham, UK, pp 59-70.

28. Lind RJ, Clough MS, Reynolds SE, Earley FGP. 1998. [ $\left.{ }^{3} \mathrm{H}\right] \mathrm{Im}-$ idacloprid labels high and low affinity nicotinic acetylcholine receptor-like binding sites in the Aphid Myzus persicae (Hemiptera: Aphidae). Pestic Biochem Physiol 62:3-14. 